\title{
Research on the Application of Fuzzy Petri Net in Personalized Education
}

\author{
Yu Nie ${ }^{1, \text { a) }}$, Guiping Su${ }^{2, \text { b) }}$, Junyi Dai ${ }^{2, c)}$,Yi Sun ${ }^{2}$,Pan Liao ${ }^{2}$ \\ ${ }^{1}$ College of Software, Jilin University, Changchun 130000, China. \\ 2 School of Computer and Control Engineering, University of Chinese Academy of Sciences, Beijing 100000, \\ China \\ a)nieyu6112@gmail.com \\ b)sugp@gucas.ac.cn \\ c)daijunyi16@mails.ucas.ac.cn
}

\begin{abstract}
It's important to control students' learning path and to know students' learning knowledge levels in individualized education systems. Based on knowledge space theory, we studied learning state space and built a learning state model through Petri net. Since all possible learning paths can be found by the Petri net, therefore, the students' knowledge levels can be labeled. To achieve the purpose of personalized learning, transitions of Petri net are applied to simulate students' learning behaviors and knowledge states of each student which revealed to be able to be expressed by the places of the Fuzzy Petri Net.
\end{abstract}

Keyword: Knowledge space; learning state; learning path; Fuzzy-Petri net

\section{INTRODUCTION}

With the maturity of information technology, learning and access to knowledge through the Internet is becoming a hot topic in recent years. More and more students choose to self-learn online especially since the implementation of the promotion of online education in China. Along with the web-based education become more popular than ever, which also brought some research issues on the table ${ }^{[1]}$. For example, how to avoid the 'self-lost' over the students, how the teachers know their students' knowledge states, and. most importantly, how to provide more humane service to the students, are the issues needed to be solved.

Driven by this demand, Adaptive Hypermedia System based Web is used more and more widely ${ }^{[2]}$ for producing adaptive educational hypermedia system. It can dynamically display the content and learning strategies according to the student's learning state. In this paper, we try to build a Learning State Model as the Domain Model, which is necessary in adaptive educational hypermedia systems, by using the Knowledge Spaces theory ${ }^{[9]}$. We can identify and control the students' learning paths through the Fuzzy Petri Net to provide individualized education.

\section{Knowledge structure theory}

The background theory of the knowledge space's conceptual framework is the knowledge space theory proposed by Dietrich Albert et al ${ }^{[3]}$. This theory provides a method based on the knowledge domain to describe the structure of a given knowledge domain. The basic idea of this theory is to express the student's knowledge as a set, and elements of the set is a group of problems that students can solve. In the knowledge space, the knowledge domain is represented by a collection containing a finite number of questions which the students can't??? solve. And each student has a description of the state of knowledge, which is a collection of questions that student can solve. 


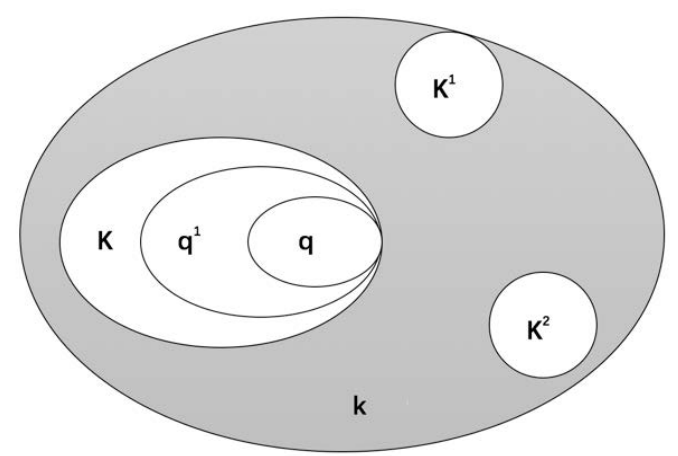

FIGURE 1. Description of knowledge status of students

The set of knowledge states is constrained by the necessary relations between various problems. In another word, it's a relation between one question and its pre-questions. For example, the constraint knowledge set Q's necessary relation means that: if a student can solve the question q' then he or she can correctly solve the question q. And we say to solve the question q is the precondition to solve the question q'. By applying the theory of knowledge space, we can build the learning state space.

Due to the existence of necessary relations between the questions, not all the subsets of questions are knowledge states. The collection of all knowledge states is called knowledge space, which consists of an empty set $\phi$ and a complete set Q. The description of knowledge status of learners is shown in Figure 1, where k represents knowledge space, $\mathrm{K}, \mathrm{K}^{1}, \mathrm{~K}^{2}$ represent knowledge levels and $\mathrm{q}, \mathrm{q}^{1}$ represent items in the knowledge states $\mathrm{K}$.

\section{Model}

3.1 The principle of the model

During the analysis process, we found that the questions in the knowledge space can be expressed by different places in the Petri Net. However, the existing knowledge space models have the problem of not being accurate enough to quantify the level of knowledge. For example, in the book "Advances in Personalized WebBased Education" we learned that the mastery of knowledge is occurring continuously over a period. Figure 2 shows how students experience the mastery during $C$ language learning process.-:

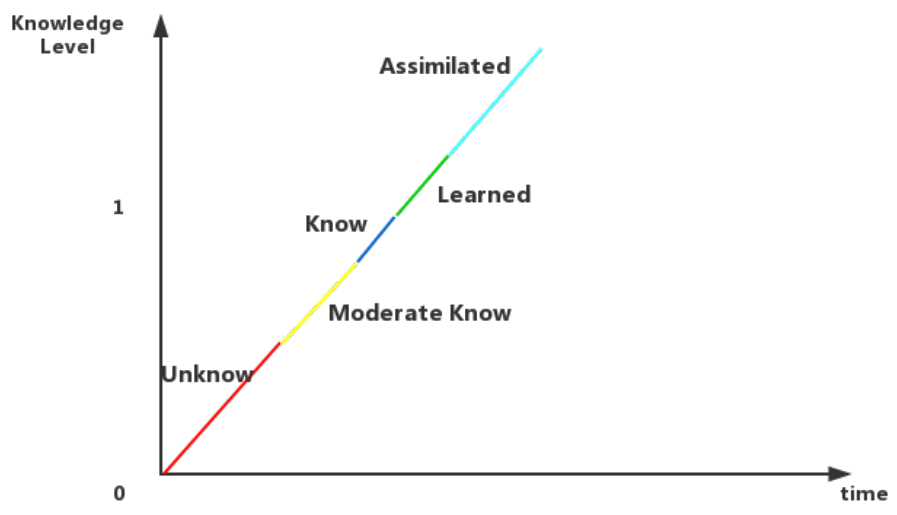

FIGURE 2. Students’ mastery process of C language learning

Moreover, we consider that to achieve the complete learning goal, the premise of learning the next point of knowledge should not the current knowledge points. In traditional education, people tend to set scores at the current 
points of knowledge (60 points) or good (80 points) to allow students to learn the next point of knowledge ${ }^{[4]}$. In that case it's not precise enough to use the Petri Net. In our study, we found that the mastery process of knowledge points can be expressed in a procedural way. For example, the mastery of knowledge experienced "Unknown", "Moderate Know", "Know", "Learned" and other stages. However, these stages are not separate. In another word, the boundaries between the various stages are not easy to find. In this study, we propose to use fuzzy logic to describe these individual processes, and map the knowledge levels to different values in the range $0-1$. And the values can be displayed on the axis, shown in Figure 3.

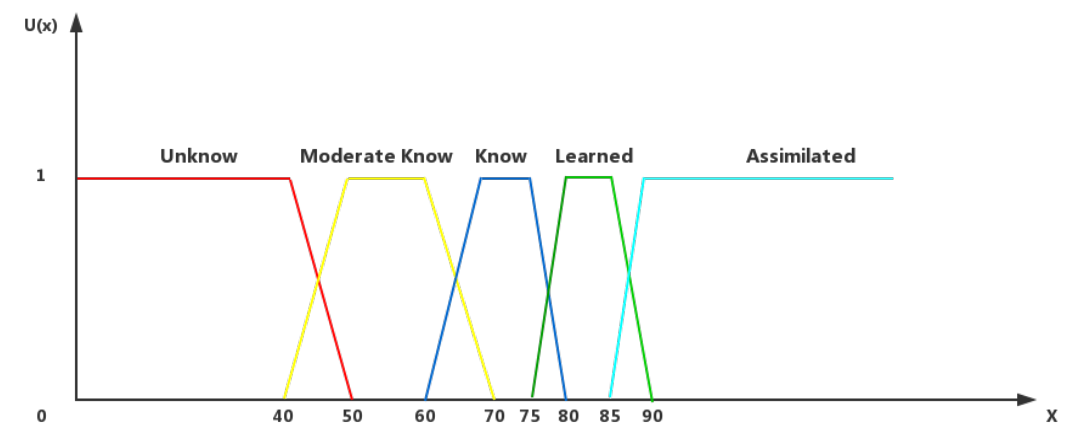

FIGURE 3. Mapping of the different knowledge levels

3.2 The definition of the model

Fuzzy Petri Net is a kind of Knowledge Model Based on Traditional Petri Nets and Fuzzy Rules.

\section{Definition 1:}

(1) Place $\mathrm{P}, \mathrm{P}=\{\mathrm{a}, \mathrm{b}, \mathrm{c}, \mathrm{d}, \mathrm{e}, \mathrm{f}\}$ represents a question or theory. If there is a token in the place, it means that this question or theory has been learned at least once ${ }^{[6]}$. And there must be a value to represent the learner's knowledge level on this question or theory. The value in the place is range from 0 to 1 .

(2) Transition T, there are two kinds of transitions. One is auxiliary transition, the other is control change. The control change $\mathrm{Ta}=\{\mathrm{T} 0, \mathrm{~T} 1, \mathrm{~T} 2, \mathrm{~T} 3\}$ represents the knowledge that have got into the output place. The auxiliary transition $\mathrm{Tb}=\{\mathrm{T} 0, \mathrm{~T} 1, \mathrm{~T} 2, \mathrm{~T} 3\}$ has no input place. The main role of $\mathrm{Tb}$ is to control the beginning of the self-learning. It represents the knowledge that goes into the output place. Its toggle rule is similar to the traditional Petri Net. Every transition only allows to be trigger only once ${ }^{[7]}$.

(3) I and $\mathrm{O}$ represent the traditional elements in the Petri Net. I: $\mathrm{P}^{*} \mathrm{~T}-\mathrm{N}$ is the input function. $\mathrm{O}: \mathrm{T}^{*} \mathrm{P}-\mathrm{N}$ is the output function. And the weight is 1 .

(4) $G$ is the rule function. Name the trigger rule of $T$ as $G(t)$. The $G(t)$ is defined in the form of "if-else" which means t can't transit without the $\mathrm{G}(\mathrm{t})$ is obeyed. This rule is aim to provide the best study strategy to the students ${ }^{[8]}$.

(5) $\mathrm{M}(\mathrm{P}-\mathrm{N})$ is the mark of the Petri Net. It's a column vector. The i-th element represents the i-th place's number of its token. M0 Indicates the initial state of the system. All the sets we can get to from the M0 is called reachability marking sets. And they are regarded as $\mathrm{R}(\mathrm{m} 0)$. Put all the marks and transitions with a graphical representation. Such a graph is called a reachable graph ${ }^{[10]}$.

3.3 Reasoning algorithm

\section{Definition 2}

KL is Knowledge level, the value of KL represents the score that students obtain in the examination.

LT is learning time, the initial value of LT is 0 . Every time a student studies a new course, the value of $\mathrm{LT}=\mathrm{LT}+1$. 


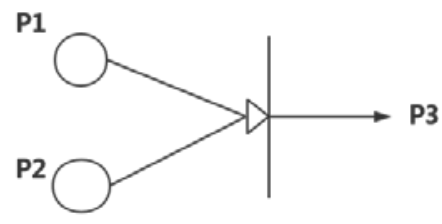

\section{FIGURE 4. Input conditions in the Petri Net}

The P1 and the P2 in the figure 4 represent the different input conditions in the Petri $\mathrm{Net}^{[9]}$. For example, when a student gets 80 scores in his or her course A (P1), and he or she just learn course A at the first time. Then P1 $=0.9, \mathrm{P} 2=0.1$, the confidence is 0.9 .

In a word, if $\mathrm{LT}=\mathrm{LT}+1$ and $\mathrm{KL}=\mathrm{KL}$, then confidence $=$ confidence -0.2 .

\section{Personalized learning path}

In the knowledge space, the transition between concepts can defined by the Learning State Space theory. This transition path is the learning path and its definition is as bellows:

Definition 3 Assuming the knowledge structure $(\mathrm{Q}, \mathrm{k})$, and the learning state path $\mathrm{X} 0, \mathrm{X} 1, \ldots, \mathrm{Xn}$ is in the (Q, k). If the following conditions are met:
(1) $\forall{ }_{c} \mathbf{I}^{\mathrm{Xi}}, \forall \mathrm{c}^{\prime} \mathbf{I} \mathrm{Q}$, if $\mathrm{c} \quad \mathrm{c}$, then $c^{\prime} \mathbf{I} \mathrm{Xi}, \mathrm{i}=0,1, \ldots, \mathrm{n}$;
(2) $\exists c^{\prime} \mathrm{Q} / \mathrm{Xi}-1$, if $\mathrm{Xi}=\mathrm{Xi}-1 \quad\{c\}, \mathrm{i}=1,2, \ldots, \mathrm{n}$.

Then the learning path is the path from zero to Q. The two conditions insure two nearby knowledge states are connected by the process of learning. We can know that a student has many paths when he or she is learning a course. For example, theoretically there are n! Paths. However, due to the existence of knowledge has consequence constraints, the actual number of the paths is much smaller than $n !^{[11]}$.

\section{Case analysis}

In this study, we use an example with six learning contenst to illustrate the above knowledge structure. The six contents are a, b, c, d, e, f. Their relationship is shown in the figure as below:

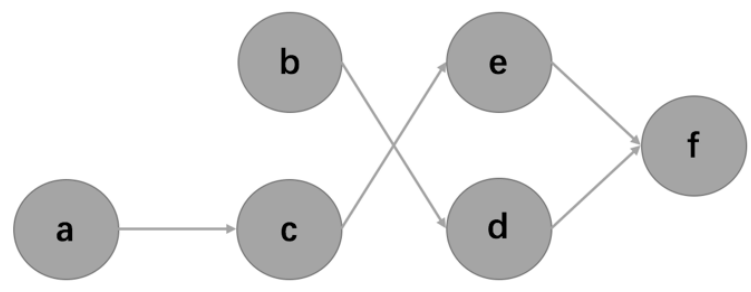

FIGURE 5. Relationship between learning contents.

According to the knowledge of learning state space, we build the Petri Net model based on the contents' relationship in the figure4. And we get the reachability graph of this model shown in Figure 6 as below: 


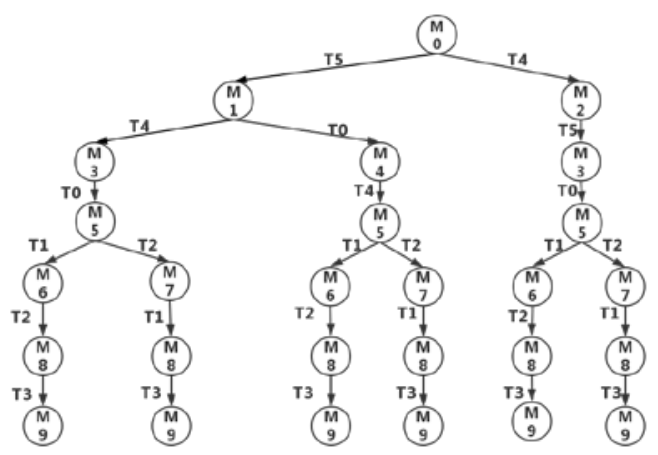

FIGURE 6. Reachability graph

The possible learning paths are shown in Figure 7.

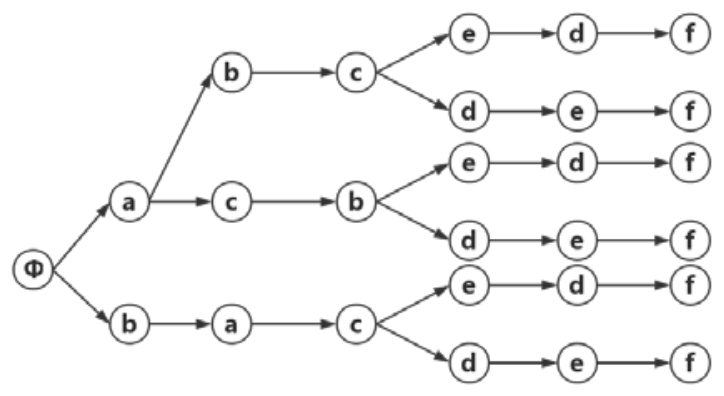

FIGURE 7. Possible learning paths

The reachability marks and relevant transitions when we use the Petri Net are shown in Table 1.

TABLE 1. Marks and transitions in the Petri Net.

\begin{tabular}{cccccc}
\hline Original[a,b,c,d,e,f] & Trigger & Result[a,b,c,d,e,f] & Original[a,b,c,d,e,f] & Trigger & Result[a,b,c,d,e,f \\
\hline $\mathrm{M}_{0}=[0,0,0,0,0,0]$ & $\mathrm{T} 5$ & $\mathrm{M}_{1}=[1,0,0,0,0,0]$ & $\mathrm{M}_{0}=[0,0,0,0,0,0]$ & $\mathrm{T} 4$ & $\mathrm{M}_{2}=[0,1,0,0,0,0]$ \\
$\mathrm{M}_{1}=[1,0,0,0,0,0]$ & $\mathrm{T} 4$ & $\mathrm{M}_{3}=[1,1,0,0,0,0]$ & $\mathrm{M}_{3}=[1,1,0,0,0,0]$ & $\mathrm{T} 0$ & $\mathrm{M}_{4}=[1,0,1,0,0,0]$ \\
$\mathrm{M}_{2}=[0,1,0,0,0,0]$ & $\mathrm{T} 5$ & $\mathrm{M}_{3}=[1,1,0,0,0,0]$ & $\mathrm{M}_{3}=[1,1,0,0,0,0]$ & $\mathrm{T} 0$ & $\mathrm{M}_{5}=[1,1,1,0,0,0]$ \\
$\mathrm{M}_{4}=[1,0,1,0,0,0]$ & $\mathrm{T} 4$ & $\mathrm{M}_{5}=[1,1,1,0,0,0]$ & $\mathrm{M}_{5}=[1,1,1,0,0,0]$ & $\mathrm{T} 1$ & $\mathrm{M}_{6}=[1,1,1,0,1,0]$ \\
$\mathrm{M}_{5}=[1,1,1,0,0,0]$ & $\mathrm{T} 2$ & $\mathrm{M}_{7}=[1,1,1,1,0,0]$ & $\mathrm{M}_{6}=[1,1,1,0,1,0]$ & $\mathrm{T} 2$ & $\mathrm{M}_{8}=[1,1,1,1,1,0]$ \\
$\mathrm{M}_{7}=[1,1,1,1,0,0]$ & $\mathrm{T} 1$ & $\mathrm{M}_{8}=[1,1,1,1,1,0]$ & $\mathrm{M}_{8}=[1,1,1,1,1,0]$ & $\mathrm{T} 3$ & $\mathrm{M}_{9}=[1,1,1,1,1,1]$ \\
\hline
\end{tabular}

But the value changes when we use the Fuzzy-Petri Net. The fuzzy data shown is from the book 'Advances in Personalized Web-Based Education' ${ }^{[4]}$. The reachability marks and relevant transitions when we use the FuzzyPetri Net are shown in the table 2.

TABLE 2. Marks and transitions in the Fuzzy-Petri Net.

\begin{tabular}{cccccc}
\hline Original[a,b,c,d,e,f] & Trigger & Result[a,b,c,d,e,f] & Original[a,b,c,d,e,f] & $\begin{array}{c}\text { Trigg } \\
\text { er }\end{array}$ & Result[a,b,c,d,e,f \\
\hline $\mathrm{M}_{0}=[0,0,0,0,0,0]$ & $\mathrm{T} 5$ & $\mathrm{M}_{1}=[0.8,0,0,0,0,0]$ & $\mathrm{M}_{0}=[0,0,0,0,0,0]$ & $\mathrm{T} 4$ & $\mathrm{M}_{2}=[0,0.9,0,0,0,0]$ \\
$\mathrm{M}_{1}=[0.8,0,0,0,0,0]$ & $\mathrm{T} 4$ & $\mathrm{M}_{3}=[0.8,0.7,0,0,0,0]$ & $\mathrm{M}_{3}=[0.8,0.7,0,0,0,0]$ & $\mathrm{T} 0$ & $\mathrm{M}_{4}=[0.8,0,0.7,0,0,0]$ \\
$\mathrm{M}_{2}=[0,0.9,0,0,0,0]$ & $\mathrm{T} 5$ & $\mathrm{M}_{3}=[0.8,0.9,0,0,0,0]$ & $\mathrm{M}_{3}=[0.8,0.7,0.7,0,0,0]$ & $\mathrm{T} 0$ & $\mathrm{M}_{5}=[0.8,0.7,0.7,0,0,0]$ \\
$\mathrm{M}_{4}=[0.8,0,0.7,0,0,0]$ & $\mathrm{T} 4$ & $\mathrm{M}_{5}=[0.8,0.7,0.7,0,0,0]$ & $\mathrm{M}_{5}=[0.8,0.7,0.7,0,0.6,0]$ & $\mathrm{T} 1$ & $\mathrm{M}_{6}=[0.8,0.7,0.7,0,0.6,0]$ \\
$\mathrm{M}_{5}=[0.8,0.7,0.7,0,0,0]$ & $\mathrm{T} 2$ & $\mathrm{M}_{7}=[0.8,0.7,0.7,0.6,0,0]$ & $\mathrm{M}_{6}=[0.8,0.7,0.7,0,0.6,0]$ & $\mathrm{T} 2$ & $\mathrm{M}_{8}=[0.8,0.7,0.7,0.6,0.6,0]$ \\
$\mathrm{M}_{7}=[0.8,0.7,0.7,0.6,0,0]$ & $\mathrm{T} 1$ & $\mathrm{M}_{8}=[0.8,0.7,0.7,0.6,0.6,0$ & $\mathrm{M}_{8}=[0.8,0.7,0.7,0.6,0.6,0]$ & $\mathrm{T} 3$ & $\mathrm{M}_{9}=[0.8,0.7,0.7,0.6,0.6,0.5]$ \\
\hline
\end{tabular}




\section{CONCLUSION}

In this paper, the knowledge space is modeled by fuzzy Petri net. We used the reachable identification set of Petri net to solve the students' current learning states. By advantages of fuzzy Petri net. In order to improve the precise for individualized education, combine with outer edge of the student's knowledge state, we also introduced the level of knowledge and learning speed of students into the model. The simulation results show that our model can dynamically plan the optimal learning path for students and predominant other method for Personalized Education.

\section{ACKNOWLEDGMENTS}

This work was financially supported by Innovative Practice Training Program for College Students of Chinese Academy of Sciences fund.

\section{REFERENCES}

1. Chen Q H, Ling P L, Xiao Y S. Method on knowledge space model based on Petri net and learning path control[J]. Jisuanji Gongcheng yu Yingyong(Computer Engineering and Applications), 2007, 43(12): 1012.Reference to a chapter in an edited book:

2. $\quad$ Albert D. Knowledge structures[M]. Springer-Verlag, 1994.

3. Albert D, Hockemeyer C. Adaptive and dynamic hypertext tutoring systems based on knowledge space theory[C]//AIED'97 Artificial Intelligence in Education. IOS Press, Amsterdam, 1997: 553-555.G.R. Mettam, How to prepare an electronic version of your article, in: B.S. Jones, R.Z. Smith (Eds.), Introduction to the Electronic Age, E-Publishing Inc., New York, 1999, pp. 281-304.

4. $\quad$ Chrysafiadi K, Virvou M. Advances in Personalized Web-Based Education[M]. Springer, 2015.

5. Haiying D, Jianshe B, Zheng Z. Study for Knowledge Representation and Acquisition Based on Fuzzy Coloured Petri Net[J]. Journal-Xian Jiaotong University, 2001, 35(10): 996-999.

6. Xiao-ling S, Ning W. Method of knowledge represen-tation based on marked fuzzy Petri net[J]. Computer Engi-neering and Applications, 2010, 46(6): 48-51.

7. Wang J, Ji Y. Application of fuzzy Petri nets knowledge representation in electric power transformer fault diagnosis[J]. Proceedings of the CSEE, 2003, 23(1): 121-125.P.G. Clem, M. Rodriguez, J.A. Voigt and C.S. Ashley, U.S. Patent 6,231,666. (2001)

8. Yuan C. The principle and application of Petri Net[J]. Beijing: Publishing house of electronics industry, 2005: 58-70.

9. Yao Y. A Petri net model for temporal knowledge representation and reasoning[J]. IEEE Transactions on Systems, Man, and Cybernetics, 1994, 24(9): 1374-1382.

10. Wang D, Yu W, Zhou Z, et al. Application of Fuzzy Sets Theory, Expert System and Artifical Neural Networks in Fault Diagnosis of Power Transformer[J]. PROCEEDINGS-CHINESE SOCIETY OF ELECTRICAL ENGINEERING, 1996, 16: 349-353.

11. Falmagne J C, Cosyn E, Doignon J P, et al. The assessment of knowledge, in theory and in practice[M]//Formal concept analysis. Springer Berlin Heidelberg, 2006: 61-79. 